\title{
Analisis Biaya Penyakit Diabetes Retinopati di Rumah Sakit
}

\author{
Cost Analysis of Diabetic Retinopathy at Hospital
}

\author{
Aulia Nadya Rizki Imansari ${ }^{*}$, Tri Murti Andayani², Dwi Endarti² \\ ${ }^{1}$ Magister Manajemen Farmasi, Universitas Gadjah Mada, Yogyakarta \\ 2 Fakultas Farmasi, Universitas Gadjah Mada, Yogyakarta \\ Corresponding author: Aulia Nadya Rizki Imansari: Email: nadyaulia7@gmail.com \\ Submitted: 16-07-2019 Revised: 26-07-2019 Accepted:08-08-2019
}

\begin{abstract}
ABSTRAK
Diabetes retinopati merupakan komplikasi mikrovaskuler diabetes melitus yang ditandai dengan kerusakan dan sumbatan pembuluh darah retina yang menjadi penyebab kebutaan. Penyakit ini membutuhkan rentang waktu pengobatan yang panjang sehingga membutuhkan biaya yang besar. Penelitian ini bertujuan untuk gambaran biaya penyakit diabetes retinopati dan mengetahui faktor - faktor yang mempengaruhi biaya penyakit. Jenis penelitian ini adalah analitik observasional dengan rancangan cross sectional study, pengambilan data dilakukan secara retrospektif. Biaya yang diperhitungkan adalah biaya medik langsung berdasarkan perspektif rumah sakit. Subjek penelitian ini adalah pasien diabetes retinopati rawat jalan periode November 2018 - Januari 2019 di rumah sakit mata Yogyakarta. Kriteria inklusi penelitian ini adalah pasien diabetes melitus tipe 2 dengan komplikasi diabetes retinopati yang menjalani terapi rawat jalan, memiliki kelengkapan data rekam medis dan kelengkapan rincian pembiayaan rumah sakit. Hasil penelitian diperoleh 60 pasien yang memenuhi kriteria inklusi. Total biaya penyakit diabetes retinopati sebesar Rp 112.710 .950 per 3 bulan rawat jalan. Rata-rata biaya per pasien Rp 1.878.516 $\pm \mathrm{Rp} 1.954 .213$. Komponen biaya terbesar adalah biaya pelayanan non operatif berupa tindakan fotokoagulasi laser. Faktor frekuensi kunjungan, jenis terapi, lama menderita diabetes retinopati berpengaruh terhadap biaya penyakit $(\mathrm{p}<0,05)$.
\end{abstract}

Kata kunci: biaya terapi; diabetes retinopati; rumah sakit mata

\section{ABSTRACT}

Diabetes retinopathy is a microvascular complication of diabetes mellitus which is characterized by damage and blockage of the retinal arteries which is the cause of blindness. This disease requires a long treatment period that requires a large amount of money. This study aims to describe the cost of diabetes retinopathy and find out the factors that influence the cost of disease. This type of research is observational analytic with a cross sectional study design, data collection is done retrospectively. Costs that are taken into account are direct medical costs based on the hospital perspective. The subjects of this study were outpatient diabetic retinopathy patients from November 2018 - January 2019 in eye hospital in Yogyakarta. The inclusion criteria of this study were type 2 diabetes mellitus patients with complications of diabetes retinopathy who underwent outpatient therapy, had complete medical record data and complete hospital financing details. The results of the study obtained 60 patients who met the inclusion criteria. The total cost of diabetes retinopathy is Rp 112,710,950 per 3 months outpatient. The average cost per patient is $\mathrm{Rp} 1,878,516 \pm \mathrm{Rp}$ $1,954,213$. The biggest cost component is the cost of non-operative services in the form of laser photocoagulation. Factors of visit frequency, type of therapy, duration of diabetes retinopathy affected the cost of the disease $(\mathrm{p}<0.05)$.

Keyword: cost of therapy; diabetes retinopathy; eye hospital

\section{PENDAHULUAN}

Diabetes Melitus (DM) merupakan suatu kelompok penyakit metabolik yang dikarakteristik oleh adanya hiperglikemia yang terjadi karena kelainan sekresi insulin, kerja insulin atau kedua-duanya (American Diabetes
Association, 2010). Hiperglikemia yang kronis pada DM akan menyebabkan komplikasi di bagian tubuh yang dapat meningkatkan risiko kematian, komplikasi yang dapat terjadi pada beberapa organ penting diantaranya gagal ginjal, serangan jantung, stroke, kehilangan 
penglihatan dan kerusakan saraf (WHO, 2016). Diabetes Retinopati (DR) merupakan salah satu komplikasi mikrovaskuler DM. Diabetes retinopati merupakan penyebab utama kebutaan dan kecacatan visual yang disebabkan oleh kerusakan pembuluh darah kecil pada retina yang menyebabkan hilangnya penglihatan secara progresif bahkan kebutaan pada pasien diabetes (WHO, 2019). Prevalensi diabetes retinopati berhubungan erat dengan kontrol glukosa dan lama penyakit diabetes. Dalam kurun waktu 20 tahun semua pasien DM tipe 1 dan lebih dari $60 \%$ pasien DM tipe 2 mengalami diabetes retinopati. Diabetes retinopati menjadi salah satu penyebab utama kebutaan pada usia 20-74 tahun (Cheung dkk., 2010)

Pengobatan DM yang bersifat terus menerus ditambah dengan komplikasi diabetes retinopati menyebabkan terapi ini membutuhkan biaya yang mahal. Proyeksi jangka panjang terhadap biaya pengobatan dan perawatan yang mahal menimbulkan dampak ekonomi bagi keluarga dan dampak ekonomi secara nasional. Cost of illness merupakan salah satu studi farmakoekonomi yang dapat digunakan untuk mengukur beban ekonomi, mengidentifikasi komponen biaya utama dan menjelaskan variasi biaya dari suatu penyakit (Andayani, 2013). Penelitian ini bertujuan untuk mengetahui gambaran biaya penyakit diabetes retinopati dan mengetahui faktor faktor yang mempengaruhi biaya penyakit.

\section{METODOLOGI Bahan}

Bahan dan sumber data dalam penelitian ini diperoleh dari rekam medik dan perincian biaya terapi pasien di bagian keuangan rumah sakit. Alat penelitian yang digunakan adalah lembar pengumpul data.

\section{Prosedur Pelaksanaan}

Penelitian ini adalah analitik observasional dengan rancangan cross sectional study pada pasien rawat jalan di rumah sakit khusus mata Yogyakarta periode November 2018 - Januari 2019. Kriteria inklusi adalah pasien diabetes melitus tipe 2 dengan komplikasi diabetes retinopati yang menjalani rawat jalan, memiliki kelengkapan data rekam medik dan memiliki kelengkapan rincian pembiayaan rumah sakit. Kriteria eksklusi adalah pasien dengan penyakit retina lain dan pasien hamil.

Hasil penelitian selama tiga bulan, peneliti mendapatkan 70 pasien. Dari seluruh pasien tersebut, hanya 60 pasien yang memenuhi kriteria inklusi penelitian ini. Data yang diperlukan dicatat pada lembar pengumpul data, meliputi : identitas pasien, nomor rekam medik, lama menderita DM, lama menderita DR, komplikasi, komorbid, biaya pemeriksaan rawat jalan, biaya administrasi, biaya pelayanan non operatif, biaya pelayanan operatif, biaya pemakaian peralatan (avastin) dan biaya obat.

\section{Analisis Hasil}

Analisis data dilakukan dengan perspektif rumah sakit, meliputi Data demografi dari faktor pasien, meliputi usia, jenis kelamin, berat badan, tinggi badan, body mass index (BMI) dan frekuensi kunjungan, data demografi dari faktor penyakit meliputi, lama menderita diabetes melitus, lama menderita diabetes retinopati, komplikasi, komorbid, jenis terapi dan tingkat keparahan dan perhitungan biaya medik langsung meliputi biaya pemeriksaan rawat jalan, biaya administrasi, biaya pelayanan non operatif, biaya pelayanan operatif, biaya pemakaian peralatan (avastin) dan biaya obat.

\section{HASIL DAN PEMBAHASAN Gambaran Karakteristik Demografi Pasien Faktor Pasien}

Karakteristik pasien yang berkaitan dengan identitas pasien dalam penelitian ini meliputi usia, jenis kelamin, body mass index (BMI) dan frekuensi kunjungan. pengelompokkan karakteristik tersebut dapat dilihat pada tabel I.

Karakteristik jenis kelamin pada penelitian ini menunjukkan bahwa prevalensi diabetes retinopati pada perempuan lebih tinggi dibandingkan laki-laki. Jumlah perempuan 39 pasien $(65,0 \%)$ dan laki-laki 21 pasien $(35,0 \%)$. Hasil penelitian sejalan dengan data riset kesehatan dasar (RISKESDAS) pada tahun 2018 bahwa prevalensi penderita diabetes melitus pada perempuan lebih tinggi daripada laki-laki. Penggolongan usia dikelompokkan menjadi tiga kelompok, yaitu usia $<45$ tahun, usia 45 - 65 tahun dan usia >65 tahun. Kelompok usia 45 - 65 tahun merupakan kelompok usia terbesar dengan jumlah 49 
Tabel I. Karaktertik pasien Diabetes Retinopati berdasarkan faktor pasien (n=67)

\begin{tabular}{llcc}
\hline \multirow{2}{*}{ Karakteristik Pasien } & Variasi Kelompok & $\begin{array}{c}\text { Jumlah Pasien } \\
\text { (n) }\end{array}$ & $\begin{array}{c}\text { Persentase } \\
\text { (\%) }\end{array}$ \\
\hline Jenis Kelamin & Laki-laki & 21 & 35,0 \\
& Perempuan & 39 & 65,0 \\
Usia (tahun) & $<45$ tahun & 3 & 5,0 \\
& $45-65$ tahun & 47 & 78,3 \\
Body Mass Index (BMI) (kg/m 2$)$ & $>65$ tahun & 10 & 16,7 \\
& $18,50-24,99$ & 38 & 63,3 \\
Frekuensi Kunjungan & $25,00-29,99$ & 17 & 28,3 \\
& $\geq 30$ & 5 & 8,3 \\
& $<3$ kali & 32 & 53,3 \\
\hline
\end{tabular}

pasien. Usia tertua pasien adalah 77 tahun dan usia paling muda adalah 41 tahun dengan ratarata usia 57,5 tahun.

Pada penelitian ini BMI dibagi menjadi 3 kategori yaitu normal $\left(18,50-24,99 \mathrm{~kg} / \mathrm{m}^{2}\right)$ sebanyak 38 pasien, kegemukan (25,00-29,99 $\mathrm{kg} / \mathrm{m}^{2}$ ) sebanyak 17 pasien dan obesitas $(\geq 30$ $\mathrm{kg} / \mathrm{m}^{2}$ ) sebanyak 5 pasien. Pada penelitian ini, sebagian besar pasien memiliki BMI normal dan hanya $8,3 \%$ pasien yang mengalami obesitas.

Berdasarkan frekuensi kunjungan, < 3 kali 32 pasien, $\geq 3$ kali 28 pasien. Pasien diabetes retinopati rawat jalan di rumah sakit khusus ini memiliki jadwal kontrol yang terjadwal, minimal 1 kali dalam sebulan. Penelitian ini dilakukan dalam 3 bulan, sebanyak 53,3\% pasien melakukan kunjungan kurang dari 3 kali dalam 3 bulan. Hal ini bisa disebabkan beberapa hal seperti pasien yang sudah merasa membaik dan tidak perlu lagi kontrol ke rumah sakit serta jarak yang ditempuh pasien ke rumah sakit cukup jauh.

\section{Faktor Penyakit}

Karakteristik pasien yang berkaitan dengan penyakit pasien dalam penelitian ini meliputi lama menderita diabetes melitus, lama menderita diabetes retinopati, komplikasi, komorbid, dan tingkat keparahan. Pengelompokkan karakteristik tersebut dapat dilihat pada tabel II.

Lama menderita diabetes melitus pada penelitian ini dikelompokkan menjadi < 15 tahun dan $\geq 15$ tahun yang mengacu pada penelitian Bressler (Bressler, 2012). Rata - rata pasien menderita DM adalah 12 tahun. Sebanyak $68,3 \%$ pasien menderita DM $<15$ tahun dan $31,7 \%$ menderita DM lebih dari
15 tahun. Lama menderita diabetes retinopati tidak menggambarkan waktu pasien pertama kali mengalami DR, karena mayoritas pasien baru memeriksakan mata setelah penglihatan mulai menurun dan muncul rasa tidak nyaman pada mata yang mengganggu saat beraktivitas. pada penelitian ini, rata - rata lama pasien menderita DR adalah 2,5 tahun dan $75 \%$ pasien sudah menderita DR lebih dari 1 tahun.

Komplikasi merupakan penyakit lain yang disebabkan adanya diabetes retinopati. pada penelitian ini komplikasi yang sering terjadi pada diabetes retinopati adalah clinically significant macular edema (CSME), vitreous hemorrage $(\mathrm{VH})$, tractional retinal detachment (TRD) dan neovascular glaucoma (NVG). Hasil penelitian menunjukkan 58,3\% pasien tidak mengalami komplikasi. CSME merupakan komplikasi yang paling banyak terjadi pada pasien yaitu sebesar $30 \%$.

Komorbid merupakan penyakit penyerta yang diderita pasien yang menjadi faktor pemburuk terhadap diabetes retinopati. penelitian ini menggunakan Charlson Comorbidity Index (CCI) untuk menggambarkan tingkat keparahan komorbid. Skor CCI dikategorikan menjadi 3 yaitu ringan (skor CCI 1-2), sedang (skor CCI 3-4) dan berat (skor CCI 25) (Huang dkk., 2014). Persentase terbesar berada pada skor CCI 1-2 sebanyak 76,7\% . Komorbid terbanyak yang dialami pasien diabetes retinopati pada penelitian ini adalah hipertensi.

Tingkat keparahan pasien diabetes retinopati dibagi menjadi dua klasifikasi, yaitu Non - Poliferative Diabetic Retinopathy (NPDR) dan Proliverative Diabetic Retinopathy (PDR). Pada penelitian ini $80 \%$ pasien terdiagnosa 
Tabel II.Karakteristik Pasien Diabetes Retinopati berdasarkan Faktor Penyakit(n=67)

\begin{tabular}{llcc}
\hline Karakteristik Pasien & Variasi Kelompok & $\begin{array}{c}\text { Jumlah Pasien } \\
\text { (n) }\end{array}$ & $\begin{array}{c}\text { Persentase } \\
\text { (\%) }\end{array}$ \\
\hline Lama DM & $<15$ tahun & 41 & 68,3 \\
Lama DR & $\geq 15$ tahun & 19 & 31,7 \\
Komplikasi & $<1$ tahun & 15 & 25,0 \\
& $\geq 1$ tahun & 45 & 75,0 \\
& Tidak Ada Komplikasi & 35 & 58,3 \\
& Ada Komplikasi & & 30,0 \\
& CSME/DME & 18 & 5,0 \\
Komorbid & VH & 3 & 3,3 \\
& TRD & 2 & 3,3 \\
& NVG & 2 & 76,7 \\
Tingkat Keparahan & Ringan (1-2) & 46 & 20,0 \\
& Sedang (3-4) & 12 & 3,3 \\
Jenis Terapi & Berat ( $\geq 5)$ & 2 & 80,0 \\
& NPDR & 48 & 20,0 \\
& PDR & 12 & 11,7 \\
& Injeksi Intravitreal anti VEGF & 7 & 36,7 \\
& Fotokoagulasi laser & 22 & 10,0 \\
& Kombinasi & 6 & 41,7 \\
\hline
\end{tabular}

Tabel III. Komponen Biaya Penyakit Diabetes Retinopati (n=60)

\begin{tabular}{lccc}
\hline Komponen Biaya & $\begin{array}{c}\text { Jumlah } \\
\text { (Rp) }\end{array}$ & $\begin{array}{c}\text { Rata-Rata } \pm \text { SD } \\
\text { (Rp) }\end{array}$ & $\begin{array}{c}\text { Persentase } \\
\text { (\%) }\end{array}$ \\
\hline Biaya Administrasi & 5.731 .400 & $95.523 \pm 57.241$ & 5,09 \\
Biaya Pelayanan Non Operatif & 68.616 .780 & $1.162 .996 \pm 1.564 .986$ & 60,88 \\
Biaya Pemeriksaan Rawat Jalan & 6.645 .000 & $132.900 \pm 59.385$ & 5,90 \\
Biaya Operasi Elektif dan ODC* & 14.617 .920 & $1.124 .455 \pm 737.820$ & 12,97 \\
Biaya Pemakaian Peralatan (Avastin) & 14.500 .000 & $1.115 .385 \pm 708.762$ & 12,86 \\
Biaya Obat & 2.599 .850 & $55.316 \pm 44.958$ & 2,31 \\
Total & 112.710 .950 & $1.878 .516 \pm 1.954 .213$ & 100,00 \\
\hline
\end{tabular}

*ODC = One Day Care

PDR. Hal ini disebabkan karena pasien baru memeriksakan mata ketika ada gangguan pada penglihatan.

Pemilihan terapi diabetes retinopati tergantung dari tingkat keparahan retinopati. alternatif terapi yang dapat diberikan adalah fotokoagulasi laser, injeksi dengan kortikosteroid dan injeksi intravitreal anti Vascular Endothelial Growth Factor (VEGF). Tujuan pemberian terapi pada pasien diabetes retinopati adalah mencegah terjadinya kebutaan dan perburukan penyakit, meningkatkan ketajaman penglihatan, mencegah neovaskularisasi dan menurunkan tingkat keparahan penyakit (Duh dkk., 2017). Pada saat ini alternatif terapi yang diterapikan untuk pasien diabetes retinopati di beberapa rumah sakit di Yogyakarta adalah dengan fotokoagulasi laser dan injeksi intravitreal anti VEGF menggunakan bevacizumab dengan merek dagang Avastin $®$.

Sebanyak 60 pasien diabetes retinopati, 35 pasien mendapatkan terapi dan 25 pasien lainnya tidak mendapatkan terapi dikarenakan hanya melakukan pemeriksaan rutin setiap bulan. Fotokoagulasi laser merupakan jenis terapi yang paling banyak didapatkan pasien, $36,7 \%$ mendapatkan terapi fotokoagulasi laser, $11,7 \%$ mendapatkan injeksi intravitreal anti VEGF dan 10\% mendapatkan kombinasi terapi dari fotokoagulasi laser dan injeksi intravitreal anti VEGF.

\section{Total Biaya Penyakit Diabetes Retinopati}

Total biaya penyakit diabetes retinopati merupakan hasil penjumlahan semua 
Tabel IV. Hasil Uji Karakteristik Pasien Diabetes Retinopati terhadap Biaya

\begin{tabular}{|c|c|c|c|c|}
\hline Karakteristik Pasien & Variasi Kelompok & $\begin{array}{l}\text { Jumlah } \\
\text { Pasien }\end{array}$ & Rata-rata & p (sig) \\
\hline \multirow[t]{2}{*}{ Jenis Kelamin } & Laki-laki & 21 & 1.971 .586 & 0,614 \\
\hline & Perempuan & 39 & 1.828 .401 & \\
\hline \multirow[t]{3}{*}{ Usia (tahun) } & $<45$ tahun & 3 & 2.429 .666 & 0,422 \\
\hline & 45-65 tahun & 47 & 1.995 .280 & \\
\hline & $>65$ tahun & 10 & 1.164 .381 & \\
\hline Body Mass Index (BMI) & $18,50-24,99$ & 38 & 1.609 .942 & 0,381 \\
\hline \multirow[t]{2}{*}{$\left(\mathrm{kg} / \mathrm{m}^{2}\right)$} & $25,00-29,99$ & 17 & 2.168 .961 & \\
\hline & $\geq 30$ & 5 & 2.932 .160 & \\
\hline \multirow[t]{2}{*}{ Lama DM } & $<15$ tahun & 41 & 2.103 .830 & 0,920 \\
\hline & $\geq 15$ tahun & 19 & 1.392 .311 & \\
\hline \multirow[t]{2}{*}{ Lama DR } & $<1$ tahun & 15 & 3.354 .729 & 0,049 \\
\hline & $\geq 1$ tahun & 45 & 1.386 .445 & \\
\hline \multirow[t]{6}{*}{ Komplikasi } & Tidak Ada Komplikasi & 35 & 2.015 .304 & 0,664 \\
\hline & Ada Komplikasi & & & \\
\hline & CSME/DME & 18 & 1.980 .378 & \\
\hline & VH & 3 & 927.433 & \\
\hline & TRD & 2 & 629.300 & \\
\hline & NVG & 2 & 1.243 .800 & \\
\hline \multirow[t]{3}{*}{ Komorbid } & Ringan (1-2) & 46 & 1.933 .766 & 0,820 \\
\hline & Sedang (3-4) & 12 & 1.595 .025 & \\
\hline & Berat $(\geq 5)$ & 2 & 2.308 .700 & \\
\hline \multirow[t]{2}{*}{ Tingkat Keparahan } & NPDR & 48 & 1.969 .951 & 0,120 \\
\hline & PDR & 12 & 1.512 .776 & \\
\hline \multirow[t]{5}{*}{ Jenis Terapi } & Injeksi intraviteral anti & 22 & 7.189 .810 & 0,000 \\
\hline & VEGF & 24 & 2.498 .240 & \\
\hline & Fotokoagulasi laser & 9 & 12.302 .355 & \\
\hline & Kombinasi & 12 & 641.029 & \\
\hline & Tidak Ada Terapi & & & \\
\hline \multirow[t]{2}{*}{ Frekuensi Kunjungan } & $<3$ kali & 32 & 513.928 & 0,000 \\
\hline & $\geq 3$ kali & 28 & 3.438 .045 & \\
\hline
\end{tabular}

komponen biaya medik yang terdiri dari biaya obat dan barang medik, biaya pelayanan non operatif, biaya pemeriksaan rawat jalan, biaya administrasi, biaya operasi elektif dan biaya pemakaian peralatan (avastin) pada pasien rawat jalan. Hasil perhitungan total biaya penyakit diabetes retinopati pada pasien rawat jalan sebesar Rp 112.710 .950 untuk 3 bulan perawatan. Rata-rata biaya per pasien adalah Rp 1.878.516 \pm Rp 1.954.213. berdasarkan tabel 4 . Komponen biaya terbesar adalah biaya pelayanan non operatif yang merupakan tindakan fotokoagulasi laser. Hal ini disebabkan karena dari 60 pasien, sebanyak 22 pasien diantaranya mendapatkan tindakan fotokoagulasi laser.

\section{Pengaruh Karakteristik Pasien Diabetes Retinopati terhadap Biaya}

Hasil uji non parametrik menggunakan uji Mann-Whitney dan Kruskal-Wallis menunjukkan bahwa tidak terdapat perbedaan terhadap biaya penyakit diabetes retinopati yang signifikan berdasarkan jenis kelamin, usia, BMI, lama DM, komplikasi, komorbid dan tingkat keparahan. Terdapat perbedaan biaya penyakit diabetes retinopati yang signifikan $(\mathrm{p}<0,05)$ berdasarkan lama DR, frekuensi kunjungan, tingkat keparahan dan jenis terapi. Lama diabetes retinopati memberikan pengaruh terhadap biaya karena berhubungan dengan progresivitas penyakitnya. Semakin lama pasien menderita diabetes retinopati, 
pasien akan mendapatkan regimen terapi yang semakin sering sehingga akan berdampak pada biaya terapi penyakit. Frekuensi kunjungan pasien ke rumah sakit memberikan pengaruh terhadap biaya karena semakin sering melakukan pemeriksaan rawat jalan di rumah sakit memberikan pengaruh terhadap biaya penyakit. Hal ini sesuai dengan penelitian yang dilakukan oleh Zhang di Singapura, bahwa kunjungan pasien diabetes melitus dengan retinopati mempunyai total biaya penyakit yang lebih besar dibandingkan dengan pasien diabetes melitus tanpa retinopati (Zhang dkk., 2017). Jenis terapi memberikan pengaruh terhadap biaya karena perbedaan jenis terapi yang didapatkan setiap pasien, semakin sering pasien mendapatkan terapi maka semakin besar biaya yang dibutuhkan.

\section{KESIMPULAN}

Total biaya penyakit diabetes retinopati sebesar Rp 112.710.950 per 3 bulan rawat jalan. Rata-rata biaya per pasien $\mathrm{Rp} 1.878 .516 \pm \mathrm{Rp}$ 1.954.213. Komponen biaya terbesar adalah biaya pelayanan non operatif berupa tindakan fotokoagulasi laser. Faktor frekuensi kunjungan, jenis terapi, lama menderita diabetes retinopati berpengaruh terhadap biaya penyakit $(\mathrm{p}<0,05)$.

\section{DAFTAR PUSTAKA}

American Diabetes Association, 2010. Standards of Medical Care in Diabetes--2010. Diabetes Care, 33: S11-S61.
Andayani, 2013. Farmakoekonomi : Prinsip Dan Metodologi. Bursa Ilmu, Yogyakarta.

Bressler, S.B., 2012. Factors Associated With Changes in Visual Acuity and Central Subfield Thickness at 1 Year After Treatment for Diabetic Macular Edema With Ranibizumab. Archives of Ophthalmology, 130: 1153.

Cheung, N., Mitchell, P., dan Wong TY, 2010. Diabetic Retinopathy. Lancet, 376 (9735): 124-126.

Duh, E.J., Sun, J.K., dan Stitt, A.W., 2017. Diabetic retinopathy: current understanding, mechanisms, and treatment strategies. JCI Insight, 2: .

Huang, Y.-Q., Gou, R., Diao, Y.-S., Yin, Q.-H., Fan, W.-X., Liang, Y.-P., dkk., 2014. Charlson comorbidity index helps predict the risk of mortality for patients with type 2 diabetic nephropathy. Journal of Zhejiang University SCIENCE B, 15: 58-66.

WHO, 2016. Global Report on Diabetes. WHO Press, Geneva.

WHO, $2019 . \quad$ WHO. URL: http://www.who.int/diabetes/en/ (diakses tanggal 13/5/2019).

Zhang, X., Low, S., Kumari, N., Wang, J., Ang, K., Yeo, D., dkk., 2017. Direct medical cost associated with diabetic retinopathy severity in type 2 diabetes in Singapore. PloS one, 12: e0180949.

Molecular Structure Calculated by Am1 Method, Indonesian Journal of Chemistry, Gadjah Mada University, Yogyakarta. 